Article

\title{
Targeting Adaptive IRE1 $\alpha$ Signaling and PLK2 in Multiple Myeloma: Possible Anti-Tumor Mechanisms of KIRA8 and Nilotinib
}

\author{
Yusuke Yamashita ${ }^{1}$, Shuhei Morita ${ }^{2, *}{ }^{0}$, Hiroki Hosoi ${ }^{1}$, Hiroshi Kobata ${ }^{1}$, Shohei Kishimoto ${ }^{2}$, \\ Tatsuya Ishibashi ${ }^{2}$, Hiroyuki Mishima ${ }^{3}{ }^{(0)}$, Akira Kinoshita ${ }^{3}{ }^{(0)}$, Bradley J. Backes ${ }^{4,5}$, \\ Koh-Ichiro Yoshiura ${ }^{3}$, Feroz R. Papa ${ }^{4,5,6}$, Takashi Sonoki ${ }^{1}$ and Shinobu Tamura ${ }^{1, *(D)}$ \\ 1 Department of Hematology/Oncology, Wakayama Medical University, Wakayama 641-8509, Japan; \\ yyyamash@wakayama-med.ac.jp (Y.Y.); h-hosoi@wakayama-med.ac.jp (H.H.); \\ ketunai@wakayama-med.ac.jp (H.K.); sonoki@wakayama-med.ac.jp (T.S.) \\ 2 First Department of Internal Medicine, Wakayama Medical University, Wakayama 641-8509, Japan; \\ kishimot@wakayama-med.ac.jp (S.K.); t1484@wakayama-med.ac.jp (T.I.) \\ 3 Department of Human Genetics, Atomic Bomb Disease Institute, Nagasaki University, Nagasaki 852-8523, \\ Japan; hmishima@nagasaki-u.ac.jp (H.M.); akino@nagasaki-u.ac.jp (A.K.); kyoshi@nagasaki-u.ac.jp (K.-I.Y.) \\ 4 Department of Medicine, University of California, San Francisco, CA 94158, USA; \\ Bradley.Backes@ucsf.edu (B.J.B.); Feroz.Papa@ucsf.edu (F.R.P.) \\ 5 Diabetes Center, University of California, San Francisco, CA 94158, USA \\ 6 Quantitative Biosciences Institute, University of California, San Francisco, CA 94158, USA \\ * Correspondence: smorita@wakayama-med.ac.jp (S.M.); stamura@wakayama-med.ac.jp (S.T.); \\ Tel.: +81-73-441-0625 (S.M.); +81-73-441-0665 (S.T.); Fax: +81-73-445-9436 (S.M.); +81-73-441-0653 (S.T.)
}

Received: 17 July 2020; Accepted: 29 August 2020; Published: 31 August 2020

\begin{abstract}
Background: Inositol-requiring enzyme $1 \alpha$ (IRE1 $\alpha)$, along with protein kinase R-like endoplasmic reticulum kinase (PERK), is a principal regulator of the unfolded protein response (UPR). Recently, the 'mono'-specific IRE1 $\alpha$ inhibitor, kinase-inhibiting RNase attenuator 6 (KIRA6), demonstrated a promising effect against multiple myeloma (MM). Side-stepping the clinical translation, a detailed UPR phenotype in patients with MM and the mechanisms of how KIRA8 works in MM remains unclear. Methods: We characterized UPR phenotypes in the bone marrow of patients with newly diagnosed MM. Then, in human MM cells we analyzed the possible anti-tumor mechanisms of KIRA8 and a Food and Drug Administration (FDA)-approved drug, nilotinib, which we recently identified as having a strong inhibitory effect against IRE1 $\alpha$ activity. Finally, we performed an RNA-sequence analysis to detect key IRE1 $\alpha$-related molecules against MM. Results: We illustrated the dominant induction of adaptive UPR markers under IRE1 $\alpha$ over the PERK pathway in patients with MM. In human MM cells, KIRA8 decreased cell viability and induced apoptosis, along with the induction of $\mathrm{C} / \mathrm{EBP}$ homologous protein (CHOP); its combination with bortezomib exhibited more anti-myeloma effects than KIRA8 alone. Nilotinib exerted a similar effect compared with KIRA8. RNA-sequencing identified Polo-like kinase 2 (PLK2) as a KIRA8-suppressed gene. Specifically, the IRE1 $\alpha$ overexpression induced PLK2 expression, which was decreased by KIRA8. KIRA8 and PLK2 inhibition exerted anti-myeloma effects with apoptosis induction and the regulation of cell proliferation. Finally, PLK2 was pathologically confirmed to be highly expressed in patients with MM. Conclusion: Dominant activation of adaptive IRE1 $\alpha$ was established in patients with MM. Both KIRA8 and nilotinib exhibited anti-myeloma effects, which were enhanced by bortezomib. Adaptive IRE1 $\alpha$ signaling and PLK2 could be potential therapeutic targets and biomarkers in MM.
\end{abstract}

Keywords: multiple myeloma; unfolded protein response; IRE1 $\alpha$; KIRA8; nilotinib; PLK2 


\section{Introduction}

Despite considerable improvements attained in multiple myeloma (MM) treatment due to the development of novel agents, most patients still relapse and become refractory to the therapy [1]. As MM cells produce extensive monoclonal immunoglobulin (Ig) proteins, they are considered to possess a well-developed endoplasmic reticulum (ER) capable of enduring excessive stress. The accumulation of unfolded and misfolded proteins in the ER stimulates an intracellular signaling pathway, known as the unfolded protein response (UPR), resulting in transcriptional and translational regulations of ER-associated proteins [2-4]. Inositol-requiring enzyme $1 \alpha$ (IRE1 $\alpha)$ is an evolutionally conserved UPR sensor protein, which is highly activated in myeloma cells [5-7]. Under remediable ER stress, IRE1 $\alpha$ plays a vital role in preserving cell viability and functioning by triggering a frameshift splicing of the X-box Binding Protein 1 (XBP1) mRNA. The translated spliced form XBP1 (sXBP1) transcriptionally upregulates genes to manage protein folding demand and sustain the cell, known as adaptive UPR (A-UPR) [8-10].

We developed an allosteric IRE1 $\alpha$ kinase inhibitor, kinase-inhibiting RNase attenuator 6 (KIRA6), which attenuates terminal UPR (T-UPR) to preserve cell function and viability under irremediable ER stress, which ameliorated the disease state in both diabetic and retinitis pigmentosa model animals [8]. We recently revealed that ABL kinases localize to the ER membrane and scaffold IRE1 $\alpha$ to activate the UPR under ER stress [10]. To confirm this, Imatinib, a Food and Drug Administration (FDA)-approved tyrosine kinase inhibitor (TKI) targeting BCR-ABL optimized for chronic myelogenous leukemia (CML), exhibited an inhibitory effect against IRE1 $\alpha$ activity [10]. Nilotinib, an equally selective but more potent inhibitor than imatinib, also exhibited an inhibitory effect on XBP1 mRNA splicing, T-UPR, and apoptosis at lower concentrations than imatinib [10]. Subsequently, we illustrated that both a mono-selective inhibitor of IRE1 $\alpha$, KIRA8 (also known as compound 18) [11], and imatinib could inhibit the ABL-IRE1 $\alpha$ axis to preserve $\beta$-cells from T-UPR and reverse autoimmune diabetes [10]. However, the anti-myeloma effects of KIRA8 and these TKIs remain only partially explored.

Although the potential of the IRE1 $\alpha-\mathrm{sXBP} 1$ pathway as a therapeutic target in several types of cancer has been extensively recognized [12], the detailed phenotypes of UPR in the patients with $\mathrm{MM}$ and the effects of IRE1 $\alpha$ inhibitors on MM remain debatable [4,13]. Notably, a study recently demonstrated the anti-tumor activity of KIRA8 against MM in human myeloma cells, a xenograft model, and patient-derived CD138 ${ }^{+}$myeloma cells [14]. Despite promising effects, the mechanism underlying the work of KIRA8 against MM remains unclear. More importantly to clinical translation, determining whether FDA-approved TKIs work equally to other IRE1 $\alpha$ inhibitors in myeloma cells is challenging. This study aimed to (i) characterize UPR activities in the bone marrow (BM) of patients with MM, and (ii) investigate the molecular mechanisms of how KIRA8 works and whether nilotinib exhibits anti-cancer effects in human myeloma cells.

\section{Results}

\subsection{UPR Signaling in the BM of Patients with Newly Diagnosed Multiple Myeloma (NDMM)}

As human myeloma cells adapt to chronic ER stress and continually activate IRE1 $\alpha-X B P 1$ signaling [2-4], we determined which endogenous UPR signaling was induced in the BM of patients with newly diagnosed multiple myeloma (NDMM) compared with the control subjects (Table S1). We retrospectively observed that the expression of $s X B P 1$ and the ER chaperone BIP mRNA (another A-UPR marker [10]) were upregulated in the BM of patients with NDMM, whereas they were sustained in the control subjects (Figure 1A,B). Generally, chronic and prolonged ER stress activated another sensor, protein kinase R-like endoplasmic reticulum kinase (PERK), to induce apoptosis through activating transcription factor 4 (ATF4) and C/EBP homologous protein (CHOP) [2-4]. In patients with NDMM, the elevation of the mRNA expression levels of ATF4 and CHOP was limited (Figure 1C,D). Despite A-UPR induction, the mRNA expression levels of thioredoxin interacting protein (TXNIP), a T-UPR marker regulated by IRE1 $\alpha$ and PERK, were not significantly increased (Figure 1E) $[15,16]$. These findings suggested that A-UPR in the IRE1 $\alpha$ pathway is dominantly activated in the BM of patients with NDMM. 

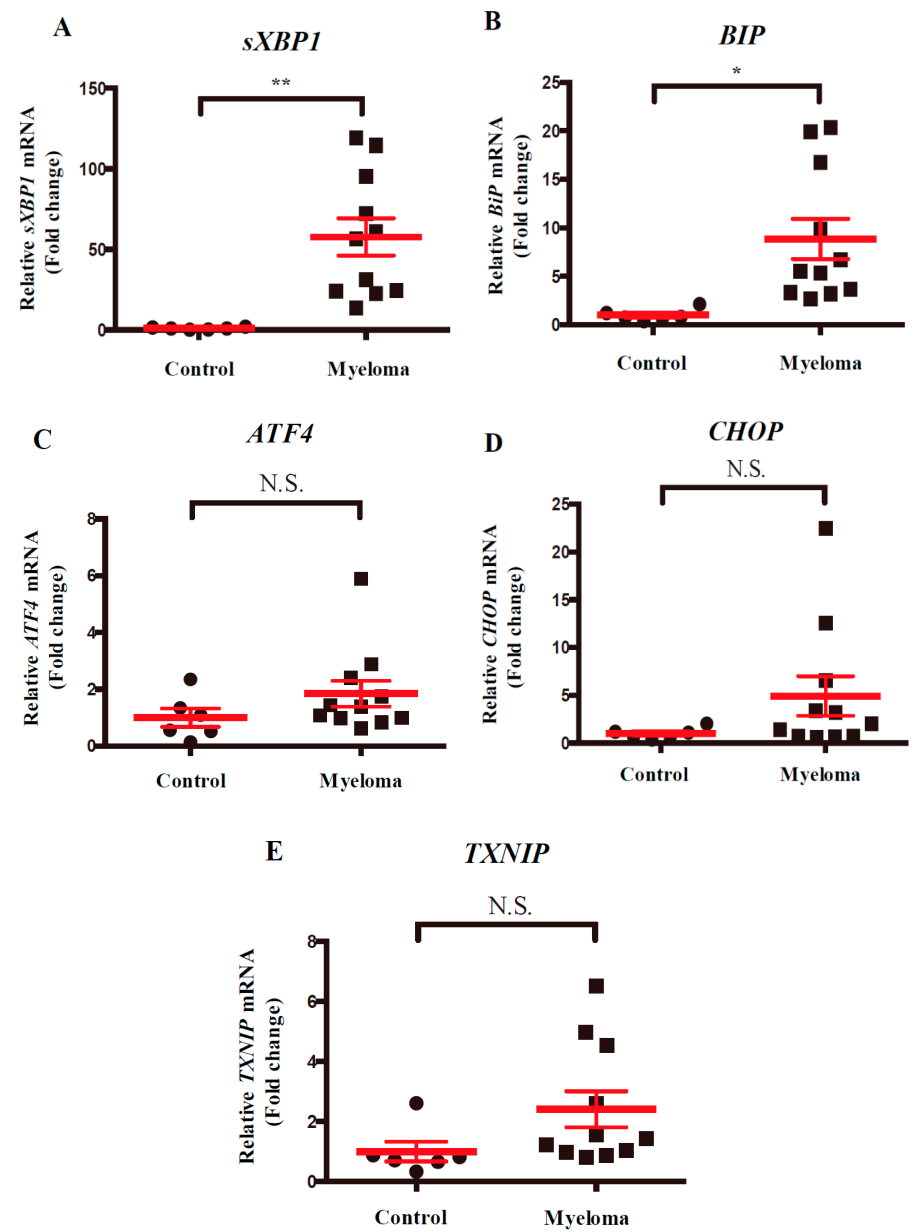

Figure 1. Unfolded protein response (UPR) markers in the bone marrow (BM) of patients with newly diagnosed multiple myeloma (NDMM). Quantitative real-time polymerase chain reaction (RT-PCR) of the relative mRNA levels of $S X B P 1(\mathbf{A}), B I P(\mathbf{B}), A T F 4(\mathbf{C}), C H O P(\mathbf{D})$, and TXNIP (E) in BM samples of patients with $\operatorname{NDMM}(n=11)$ and control subjects $(n=6)$. Each symbol denotes an individual patient. The data shown are presented as the mean \pm standard error of the mean (SEM). N.S., non-significant. ${ }^{*} p<0.05,{ }^{* *} p<0.01$.

\subsection{Effects of KIRA8 and PERK Inhibitors on Human Myeloma Cells}

To determine the effects of KIRA8 on human myeloma cells, we used IM-9 cells, which exhibit splicing of XBP1 mRNA even at the baseline (21.8\% of spliced to total XBP1 mRNA ratio) (Figure 2B). To induce global UPR, we used thapsigargin, which inhibits ER $\mathrm{Ca}^{2+}$-dependent ATPase. In IM-9 cells, KIRA8 inhibited SXBP1 mRNA, both at the baseline and even under the robust UPR, with $500 \mathrm{nM}$ of thapsigargin (Figure 2B). In IM-9 cells, $10 \mu \mathrm{M}$ of KIRA8 markedly decreased the cell viability analyzed by the cell counting kit-8 (CCK-8) assay and trypan blue exclusion assay, along with the apoptosis induction (Figure 2C-E, Figure S1A).

Recently, we reported that KIRA8 led to the reciprocal hyperactivation of PERK and apoptotic signaling, halting tumor growth and survival during mild ER stress in pancreatic neuroendocrine tumors (p-NET) [17]. Surprisingly, KIRA8 increased the PERK-related CHOP mRNA expression in a dose-dependent manner in IM-9 cells, as shown in p-NET (Figure 2F). Notably, the IM-9 cells were mildly ER-stressed at the baseline (Figure 2B), suggesting that both the IRE1 $\alpha$ and PERK pathways were continuously activated at the baseline. To investigate the compensatory signaling through a parallel pathway of IRE1 $\alpha$ and PERK under mild ER stress, we further assessed the effect of two highly selective PERK inhibitors, GSK2606414 and AMG PERK 44 (AMG) [18,19]. 
$\mathbf{A}$

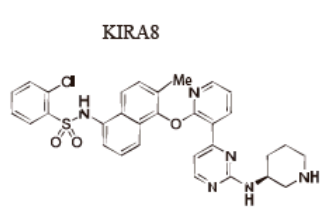

B

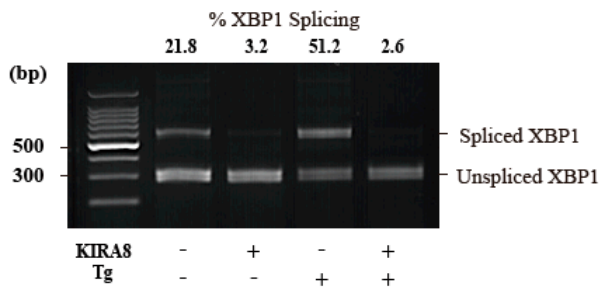

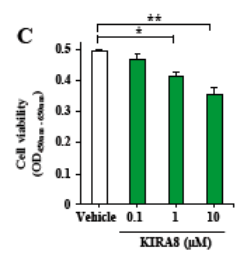

D

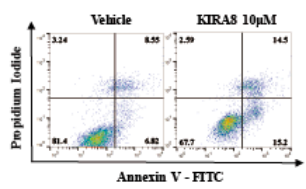

$\mathbf{E}$
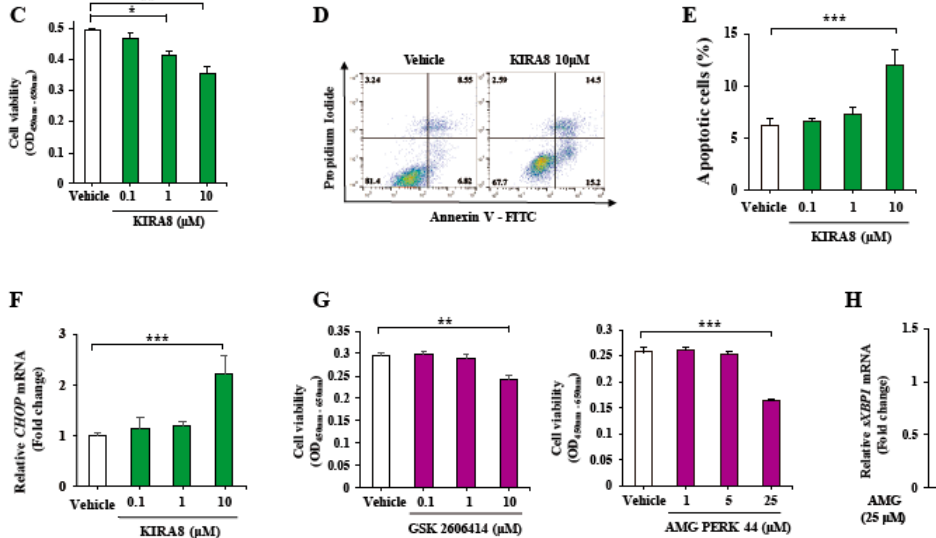

G
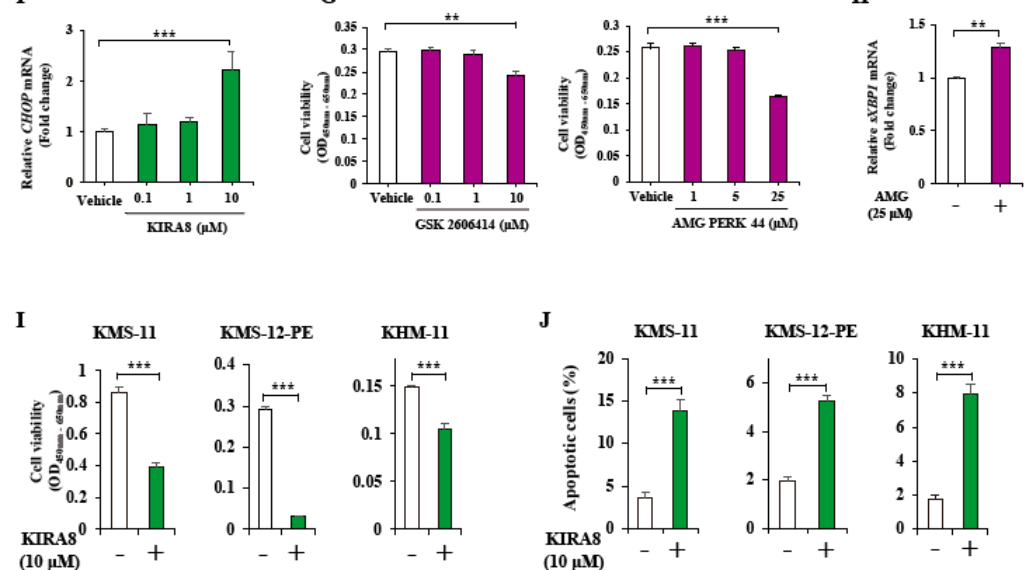

Figure 2. Effects of kinase-inhibiting RNase attenuator 8 (KIRA8) and protein kinase R-like endoplasmic reticulum kinase (PERK) inhibitors on human myeloma cells. (A) The structure of KIRA8 (B) Pst I-digested X-box Binding Protein 1 (XBP1) cDNA amplicons from IM-9 cells treated for $24 \mathrm{~h}(\mathrm{~h})$ with vehicle (dimethyl sulfoxide, DMSO) or $10 \mu \mathrm{M}$ of KIRA8 and $500 \mathrm{nM}$ of thapsigargin (Tg). Top, the intensity ratios of the spliced form to the total XBP1. (C-E) IM-9 cells were treated with vehicle (DMSO) or KIRA8 with the indicated concentrations for $24 \mathrm{~h}$. (C) The cell viability was assessed using the cell counting kit-8 (CCK-8) assay. (D,E) Apoptosis was assessed using FACS analysis of annexin V/propidium iodide (PI)-stained myeloma cells treated with vehicle or KIRA8 for $24 \mathrm{~h}$. Annexin V-positive/PI-negative cells are regarded as cells in apoptosis. Representative FACS plots show annexin V/PI-stained cells (D) and the \% apoptotic cells (E). (F) Quantitative RT-PCR of the relative CHOP mRNAs from IM-9 cells treated with vehicle (DMSO) or KIRA8 for $24 \mathrm{~h}$. (G) The cell viability in IM-9 cells treated with GSK 2606414 or AMG for $24 \mathrm{~h}$. (H) Quantitative RT-PCR of the relative sXBP1 mRNA levels from IM-9 cells treated with vehicle (DMSO) or $25 \mu \mathrm{M}$ of AMG for $24 \mathrm{~h}$. (I,J) The cell viability (I) and apoptosis (J) assay in three different human myeloma cells-KMS-11, KMS-12-PE, and KHM-11-treated with vehicle (DMSO) or $10 \mu \mathrm{M}$ of KIRA8 for $24 \mathrm{~h}$. The data shown are the mean \pm SEM. For all experiments, three independent biological samples were used. ${ }^{*}, p<0.05 ;{ }^{* *}, p<0.01$; $* * *, p<0.001$.

Both GSK2606414 (at $10 \mu \mathrm{M}$ ) and AMG (at $25 \mu \mathrm{M}$ ) significantly decreased the cell viability in IM-9 cells (Figure 2G). At this point, AMG elevated the expression levels of $s$ XBP1 mRNA, suggesting compensation through the IRE1 $\alpha$ pathway (Figure 2H). To further validate the effect of KIRA8 in other human myeloma cell lines, we used KMS-11, KMS-12-PE and KHM-11 cells. KIRA8 decreased the cell viability and increased apoptosis in all three cell lines (Figure 2I,J). Together, the KIRA8 and PERK inhibitors demonstrated anti-myeloma effects with induction of the compensational pathway. 


\subsection{Effects of Combined Treatment with KIRA8 and Bortezomib in Human Myeloma Cells}

In human myeloma cells, bortezomib induces UPR signaling activated by the accumulation of misfolded proteins within the ER [2-4]. Bortezomib enhances the anti-myeloma effects of several chemotherapeutic agents. Thus, we analyzed the combined effect of KIRA8 and bortezomib in IM-9 cells. The combined treatment with bortezomib and KIRA8 at $10 \mu \mathrm{M}$ decreased the cell viability more than KIRA8 alone (Figure 3A, Figure S1B). Next, we determined whether the observed effects of the combined treatment on the cell viability could be related to apoptosis. The combined treatment markedly increased the apoptosis of IM-9 cells compared with bortezomib alone (Figure 3B,C). The effect on apoptosis was highlighted for the combination treatment with $5 \mathrm{nM}$ of bortezomib and $10 \mu \mathrm{M}$ of KIRA8 (Figure 3B,C). As previous studies demonstrated the UPR induction by bortezomib [2-4], we analyzed the effect of KIRA8 in combination with thapsigargin in IM-9 cells. Like bortezomib, the combination of KIRA8 and thapsigargin exhibited stronger effects than KIRA8 alone on the cell viability reduction and the apoptosis induction (Figure 3D, Figure S1C). Thus, the combination of KIRA8 and bortezomib exhibited stronger anti-tumor effects on myeloma cells than KIRA8 alone.
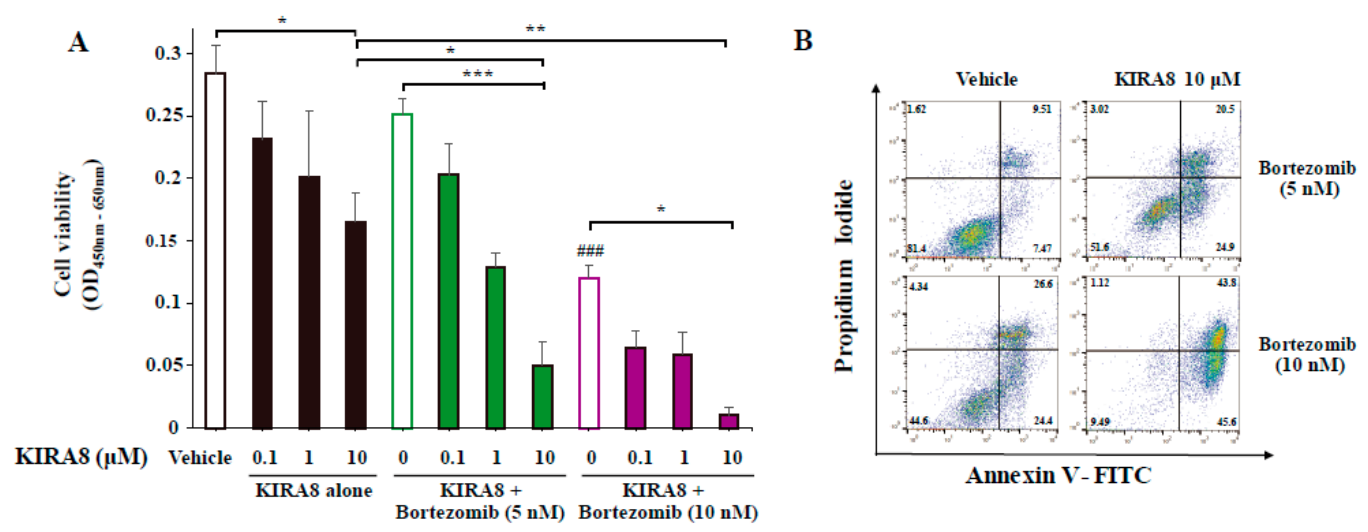

C

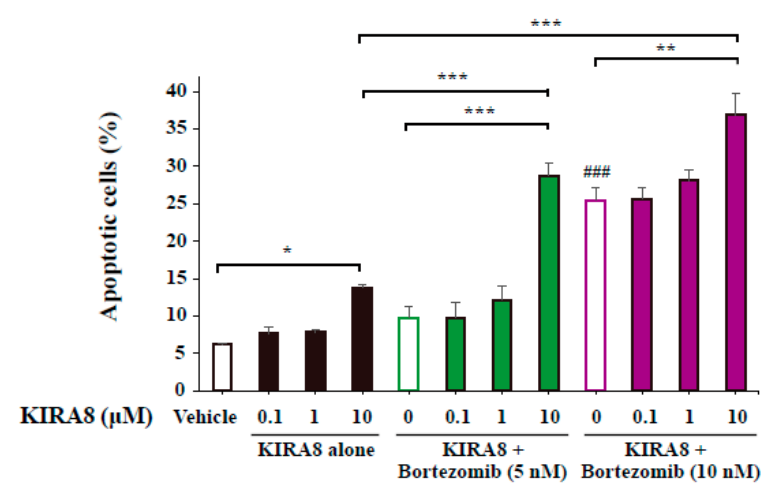

D

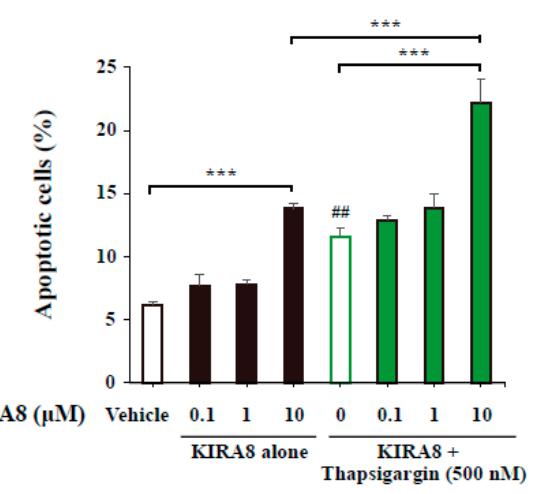

Figure 3. Anti-tumor effects from a combination with KIRA8 and bortezomib in IM-9 cells. (A) The cell viability assessed by the CCK-8 assay in IM-9 cells treated with vehicle (DMSO) or the indicated concentrations of KIRA8 for $1 \mathrm{~h}$, followed by the indicated concentrations of bortezomib for $24 \mathrm{~h}$. Three independent biological samples were used. (B,C) The \% apoptotic cells in IM-9 cells treated with vehicle (DMSO) or the indicated concentrations of KIRA8 for $1 \mathrm{~h}$, followed by the indicated concentrations of bortezomib for $24 \mathrm{~h}$. The representative FACS plots show annexin V/PI-stained cells (B) and the \% apoptotic cells (C). Four independent biological samples were used. (D) The \% apoptotic cells in IM-9 cells treated with vehicle (DMSO) or the indicated concentrations of KIRA8 for $1 \mathrm{~h}$, followed by $500 \mathrm{nM}$ of $\mathrm{Tg}$ for $24 \mathrm{~h}$. Four independent biological samples were used. The data shown are the mean $\pm \mathrm{SEM}$. $*, p<0.05 ; * *, p<0.01 ; * * *, p<0.001 .{ }^{\#}, p<0.01$; \#\#, $p<0.001$; vs. vehicle. 


\subsection{Nilotinib Exhibits Anti-Myeloma Effects}

Next, from the clinical aspect, we investigated whether nilotinib could induce anti-myeloma effects as KIRA8 does [10]. We selected nilotinib with these two reasons: First, among the FDA-approved drugs, high-throughput screening using a DELFIA assay identified nilotinib as a promising candidate inhibitor of IRE1 $\alpha$ autophosphorylation [20]. Second, we previously demonstrated that nilotinib exerted robust inhibition of IRE1 $\alpha$ activity by anchoring ABL in the cytosol with an IC50 of $3.21 \mu \mathrm{M}$ for attenuating XBP1 splicing [10]. Surprisingly, nilotinib reduced cell viability with $10.37 \mu \mathrm{M}$ of IC50 showing an induction of apoptosis (Figure $4 \mathrm{~A}, \mathrm{~B}$ ). Nilotinib was confirmed to inhibit $s X B P 1 \mathrm{mRNA}$ expression as we previously reported a strong inhibitory effect of IRE1 $\alpha$ activity in pancreatic $\beta$-cells, whilst it induced CHOP mRNA expression (Figure 4C). Finally, the anti-myeloma effects of nilotinib were enhanced by bortezomib (Figure 4D). In summary, similarly to KIRA8, FDA-approved nilotinib exhibited novel anti-myeloma effects enhanced by bortezomib.

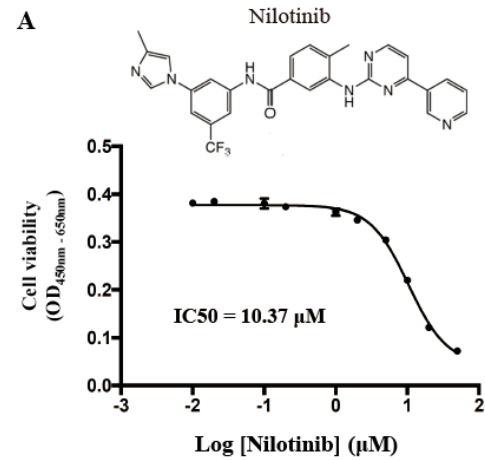

C
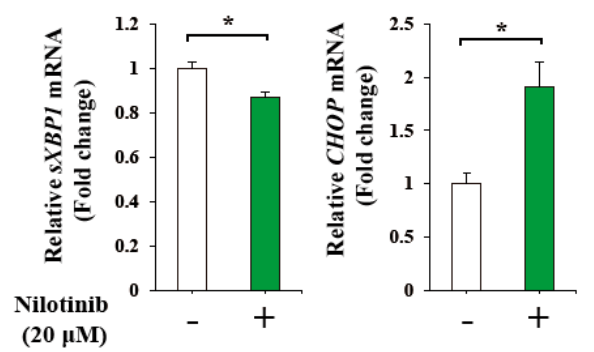

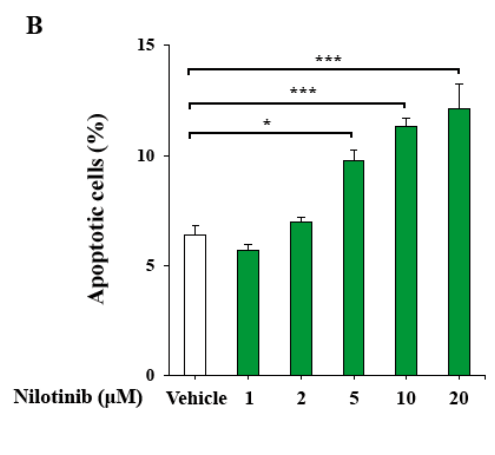

D

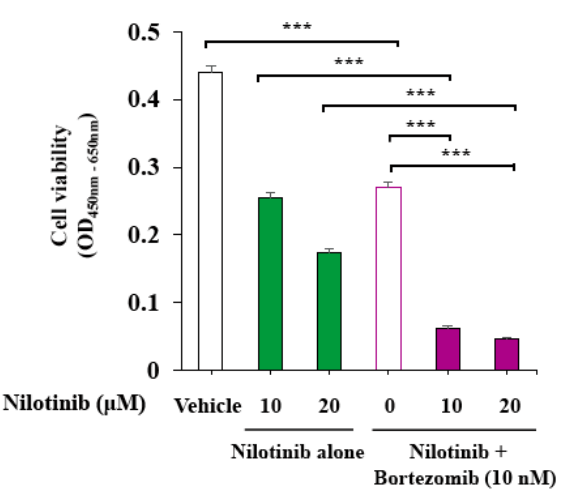

Figure 4. Anti-myeloma effects of nilotinib in IM-9 cells. (A) The structure of nilotinib and the cell viability assessed by the CCK-8 assay in IM- 9 cells treated with the indicated concentrations of nilotinib for $24 \mathrm{~h}(n=4)$. (B) The \% apoptotic cells in IM-9 cells treated with vehicle (DMSO) or the indicated concentrations of nilotinib for $24 \mathrm{~h}(n=3)$. (C) Quantitative RT-PCR of the relative $S$ XBP1 and CHOP mRNA levels from IM-9 cells treated with vehicle (DMSO) or $20 \mu \mathrm{M}$ of nilotinib for $24 \mathrm{~h}(n=3)$. (D) The cell viability assessed by the CCK-8 assay in IM-9 cells treated with vehicle (DMSO) or the indicated concentrations of nilotinib and bortezomib for $24 \mathrm{~h}(n=4)$. The data shown are as the mean \pm SEM. ${ }^{*}, p<0.05 ;{ }^{* *}, p<0.01 ;{ }^{* * *}, p<0.001$.

\subsection{Gene Expression Profile Induced by KIRA8 in Human Myeloma Cells}

To explore the mechanisms of anti-myeloma effects of KIRA8, the transcriptome profiling was examined by the RNA-sequence (RNA-seq) analysis in IM-9 cells. A heatmap visualized the expression patterns of the 64,985 identified differentially expressed genes (DEGs), which were then hierarchically categorized into 17 clusters through cluster analysis (Figure 5A, Table S3). The DEGs in cluster 16 were those inhibited by all KIRA8-based treatments (Figure 5A, dotted square). We further identified the 30 
most strongly downregulated protein-coding DEGs in IM-9 cells treated with KIRA8 alone (Figure 5B). Amongst the top 30 abundant genes, we focused on the PLK2 in cluster 16, a member of the 'polo' family of serine/threonine protein kinases, which plays a vital role in normal cell division (Figure 5B, arrow) [21]. The 64,985 identified DEGs were classified into different functional categories based on the Gene Ontology (GO) term enrichment analysis for molecular function. The most significantly downregulated DEGs were associated with the GO terms negative regulation of (i) structural constituent of ribosome, (ii) protein kinase activity, and (iii) protein serine/threonine kinase activity $(\log \mathrm{P}<-5$; Figure 5C, Table S4). Among the genes associated with the kinase activity, PLK2 was the most significantly downregulated by the KIRA8 treatment.
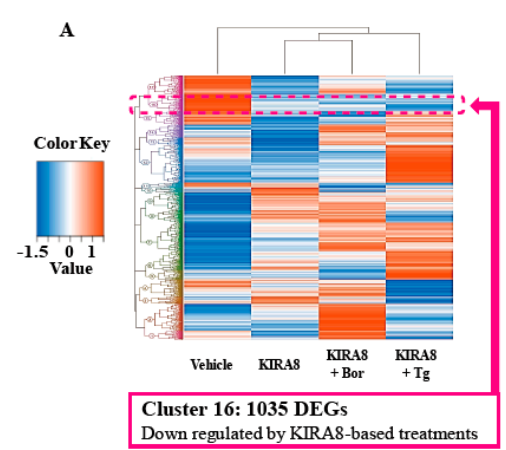

C

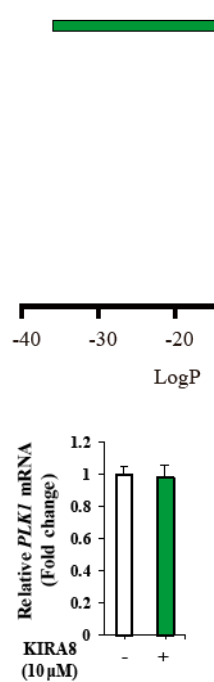
Cluster 16: 1035 DEGs
Down regulated by KIRA8-based treatments

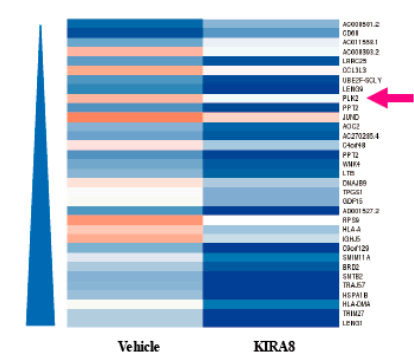
Vehicle KIRA8 


\subsection{The Regulation of PLK2 by KIRA8 and the Effects of Its Inhibition on MM Cells}

To confirm the results of RNA-seq analysis, we further examined the PLK2 gene expression in IM-9 cells. KIRA8 suppressed the PLK2 expression, both at the mRNA and protein levels (Figure 5D,E), and demonstrated a limited effect on the mRNA expression of PLK1 (Figure 5D), the most intensively explored PLK family member [21,22]. Next, we used doxycycline (DOX)-inducible IRE1 $\alpha$-overexpressing INS-1 insulinoma cells to confirm the specific effect of IRE1 $\alpha$ on PLKs [23]. Despite the limited effect on PLK1 mRNA, the IRE1 $\alpha$ overexpression significantly increased, both at the mRNA and protein levels of the PLK2 expression (Figure 6A,B). Conversely, AMG increased the mRNA expression of PLK2, but not PLK1, potentially under the induction of $s X B P 1$ or the inhibition of regulated IRE1-dependent decay (RIDD) (Figure 2H, Figure 6C) [24].

The PLK family, including PLK1 and PLK2, is involved in cell-cycle progression [21,22]. Accordingly, we examined these biological characteristics of PLK2 in myeloma cells. A PLK2-dominant inhibitor, TC-S7005, significantly reduced the cell viability and increased apoptosis in IM-9 myeloma cells (Figure 6D,E) [25]. In addition, TC-S7005 reduced the fraction of these cells in the $\mathrm{G}_{2} / \mathrm{M}$ phase (Figure 6F). Likewise, the upstream IRE1 $\alpha$ pathway inhibition by KIRA8 decreased the cells in the $\mathrm{G}_{2} / \mathrm{M}$ phase, as shown in the PLK2 inhibition (Figure 6G). Together, PLK2 expression, but not PLK1, was regulated by IRE1 $\alpha$, and its pharmacological inhibition induced apoptosis, demonstrating the cell-cycle arrest in human myeloma cells.

\subsection{High Expression of PLK2 mRNA and Protein in NDMM}

Finally, encouraged by the regulatory effect of IRE1 $\alpha$ on PLK2, we assessed if the PLK2 expression was, indeed, increased in patients with myeloma. As anticipated, the PLK2 mRNA levels were significantly increased ( $>20$ times) in the BM of patients with NDMM who attained a complete response receiving bortezomib-based treatment and high-dose melphalan compared with those of control subjects (Figure $6 \mathrm{H}$ ). For further confirmation, we performed immunohistochemical analysis with the anti-PLK2 antibody in a BM clot of a patient with NDMM (Case MM-11). In this study, the PLK2 protein was highly expressed in BM cells, which were merged with $\mathrm{CD} 138^{+}$cells (Figure 6I). Overall, these findings suggested that the mRNA and protein expressions of PLK2 were increased in human myeloma cells. 
$\mathbf{A}$

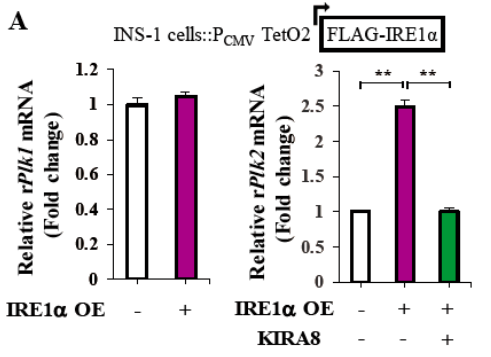

C
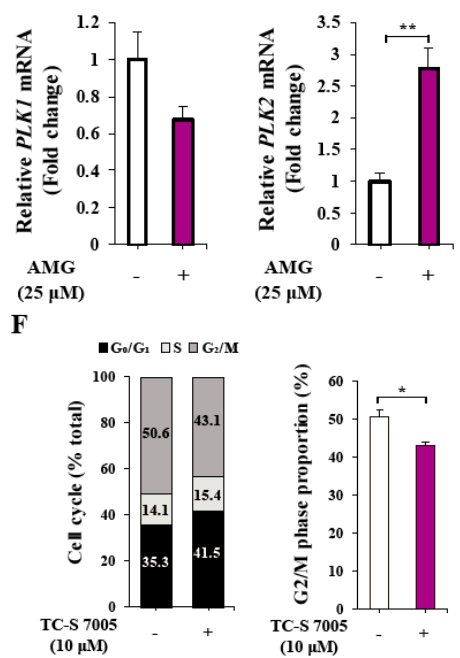

H

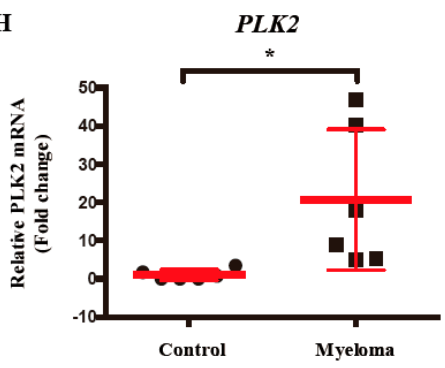

B

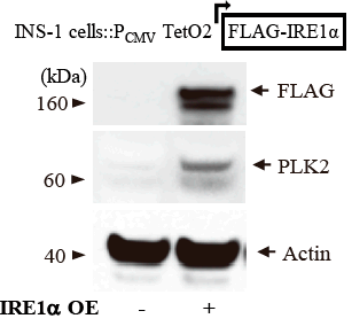

D

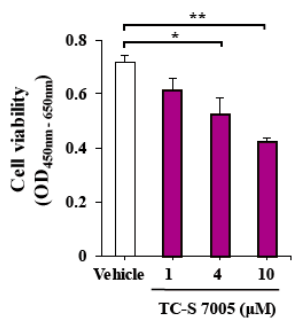

E

G

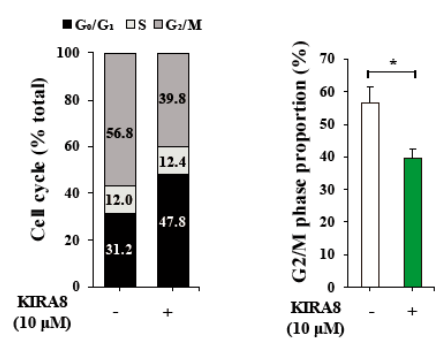

I

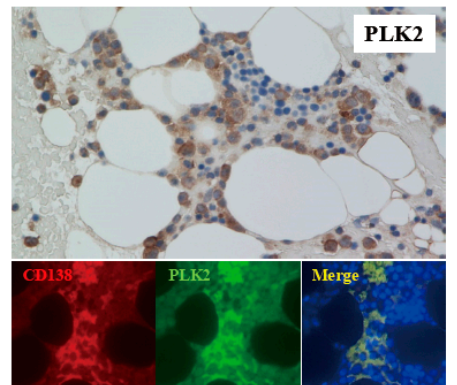

Figure 6. PLK2 expression was IRE1 $\alpha$-dependent and its inhibitor exhibited anti-myeloma effects in IM-9 cells. PLK2 protein and mRNA were expressed strongly in patients with NDMM. (A,B) Quantitative RT-PCR of relative rat Plk1 and Plk2 mRNA levels in duplicate (A) and western blotting of PLK2 protein (B) from doxycycline (DOX)-inducible IRE1 $\alpha$-overexpressing INS-1 insulinoma cells treated with vehicle (DMSO) or $0.5 \mu \mathrm{M}$ of KIRA8 with or without $1 \mu \mathrm{g} / \mathrm{mL}$ of DOX for $24 \mathrm{~h}$. (C) Quantitative RT-PCR of the relative PLK1 and PLK2 mRNA levels from IM-9 cells treated with $25 \mu \mathrm{M}$ of AMG for $24 \mathrm{~h}$ $(n=3)$. (D) The cell viability in IM-9 cells treated with vehicle (DMSO) or the indicated concentrations of TC-S 7005 for $72 \mathrm{~h}(n=3)$. (E) Annexin V-positive/PI-negative IM-9 cells treated with vehicle (DMSO) or $10 \mu \mathrm{M}$ of TC-S 7005 for $72 \mathrm{~h}(n=3)$. (F,G) The \% components of cell-cycle phases and \% cells in the $\mathrm{G}_{2} / \mathrm{M}$ phase in IM-9 cells treated with vehicle (DMSO) and $10 \mu \mathrm{M}$ of TC-S 7005 for $72 \mathrm{~h}(\mathrm{~F})$ or $10 \mu \mathrm{M}$ of KIRA8 (G) for $24 \mathrm{~h}$. For these experiments, four independent biological samples were used. $(\mathbf{H})$ Quantitative RT-PCR of relative PLK2 mRNA levels in BM samples of control subjects $(n=6)$ and patients with NDMM who attained a complete response receiving bortezomib-based treatment and high-dose melphalan $(n=6)$. (I) The expression of PLK2 protein in the BM clot specimen of a patient with NDDM was confirmed by immunohistochemical analysis with anti-PLK2 antibodies (magnification, $\times 200$ ). The rabbit immunoglobulin $\mathrm{G}$ control was negative (data not shown). Immunofluorescence at higher magnification illustrates the expression of the PLK2 protein (green) in CD138 ${ }^{+}$myeloma cells (red). DAPI (4',6-diamidino-2-phenylindole; blue) was used as a nuclear counterstain. The data shown are the mean \pm SEM. ${ }^{*}, p<0.05 ;{ }^{* *}, p<0.01$. 


\section{Discussion}

Although the IRE1 $\alpha-X B P 1$ pathway has been used as a therapeutic target, the expression of UPR markers remains only partially explored in patients with MM. This study demonstrated that A-UPR markers in the IRE1 $\alpha$ pathway were dominantly increased over the PERK pathway in patients with NDMM compared with the control subjects [26,27]. Conversely, TXNIP, a T-UPR marker, was not increased. Motivated by these findings, we further explored the effect of the IRE1 $\alpha-X B P 1$ pathway on the anti-tumor activity against MM by using the novel 'mono'-specific inhibitor of IRE1 $\alpha$, KIRA8, in this study.

To date, several compounds targeting the IRE1 $\alpha$ RNase activity have exhibited anti-tumor activity in in vitro and xenograft models $[3,13,28-30]$. Remarkably, KIRA8 was recently demonstrated to decrease the cell viability and growth of human myeloma cells and exhibit anti-tumor activity in a xenograft model [14]. Here, we confirmed the anti-myeloma effects of KIRA8 as in the previous report [14]. Next, we showed that specific inhibition of the IRE1 $\alpha$ kinase domain by KIRA8 was coupled with CHOP expression, which could be associated with PERK activation, whereas selective PERK inhibitors conversely decreased the cell viability with the activation of IRE1 $\alpha$. Similar reciprocal effects of IRE1 $\alpha$-PERK were reported in p-NET [17]. Thus, in neoplasms driven from professional secretory cells, such as myeloma or $\beta$-cells, the balance of IRE1 $\alpha$-PERK activities could be essential for the survival and proliferation of tumors under basal ER stress.

Bortezomib was reported to exhibit an additional effect on growth suppression in myeloma cells in which the IRE1 $\alpha$ kinase domain is knocked down [14]. Consistently, our study demonstrated that the combination of KIRA8 and bortezomib more strongly induced apoptosis in myeloma cells compared with monotherapy with either agent. In daily clinical practice, proteasome inhibitors are primarily used in combination with antibody drugs and other molecular-targeted drugs [31]. Hence, KIRA8 could be a novel molecular-targeted drug for $\mathrm{MM}$, and its combination with proteasome inhibitors is considered a potent regimen.

Nilotinib is a close analogue of imatinib with approximately 20-fold higher potency inhibition of BCR-ABL, the oncogenic driver in CML [32]. Recently, we demonstrated that nilotinib attenuated IRE1 $\alpha$ signaling under prolonged ER stress by anchoring ABL in the cytosol in islet $\beta$-cells [10]. In our study, the ABL-IRE1 $\alpha$ signaling inhibition by nilotinib resulted in anti-myeloma effects, demonstrating the PERK pathway activation and enhanced cytotoxic effects with bortezomib. Although nilotinib has not been approved for MM treatment yet, its novel molecular mechanism could have the potential to expand the repertoire of therapeutic options in patients with MM.

The comprehensive transcriptome analysis by RNA-seq highlighted PLK2 as a key downstream target of the IRE1 $\alpha$ kinase activation, possibly followed by a XBP1 or RIDD target [24]. Although there is a limitation in the cluster analysis of RNA-seq data that we performed the limited combination of KIRA8 based-treatment without bortezomib or thapsigargin alone, the PLK2 was a non-biased top-hit target by KIRA8 (Figure $5 \mathrm{~B}$ ) and its reduction by KIRA8 were clearly confirmed by quantitative PCR and western blot (Figure 5D,E).

Our findings demonstrated that KIRA8 treatment suppressed the transition to the $G_{2} / M$ phase in myeloma cells, followed by the PLK2-dominant inhibitor exhibiting a similar effect as KIRA8. Compared with the abundant evidence of PLK1 inhibitors against several cancer types [22,33], the evidence regarding PLK2 inhibitors is limited. Based on the results of this and a limited number of preclinical studies, PLK2 could also serve as a potential therapeutic target for several cancer types by regulating apoptosis and cell proliferation [34].

This study has some limitations worth acknowledging. First, the sample size was small. Nevertheless, this is the first pilot study to demonstrate that the PLK2 expression was increased in the BM of patients with myeloma, whereas it was constant in those of control subjects. In addition, a recent study reported that high PLK2 expression correlated with poor outcomes in colorectal cancer (CRC) and served as a prognostic biomarker [34]. Our study raises the possibility that high PLK2 expression could be a novel biomarker for not only CRC but also MM. Thus, further studies are 
warranted to establish the role of PLK2 as a biomarker and, more importantly, to determine if PLK2 expression correlates with the outcomes in MM.

In conclusion, this study demonstrated the dominant activation of the adaptive IRE1 $\alpha$ pathway in patients with NDMM and the anti-myeloma effects of KIRA8 and nilotinib with the reciprocal induction of CHOP. In addition, this study identified PLK2 as a novel key target of IRE1 $\alpha$, demonstrating its inhibitor-induced anti-myeloma effects. Overall, this study supports the promising therapeutic strategy with KIRA8 and nilotinib against MM by providing molecular and human pathological evidence regarding MM, as well as the likelihood of PLK2 as a novel therapeutic target and biomarker for MM.

\section{Materials and Methods}

\subsection{Clinical Data}

We retrospectively assessed 27 patients with NDMM at Wakayama Medical University (Wakayama, Japan) from January 2015 to January 2019. Among these patients with NDDM, we conducted a cross-sectional observational study of 11 consecutive patients (7 males and 4 females) receiving bortezomib- or lenalidomide-based induction treatment and having no exclusion criteria described below. We collected the patients' pre-treatment BM samples. The exclusion criteria were; inaccessible or incomplete medical records, less than 10\% myeloma cells in BM aspiration, and low quality of RNA obtained from the BM sample. The median age of MM onset was 63 (range: 43-77) years. All patients with MM were diagnosed according to the diagnostic criteria developed by the International Myeloma Working Group [35]. In addition, we enrolled six patients who were newly diagnosed with limited-stage diffuse large B-cell lymphoma, who had apparently normal BM trephine specimens, as the control group and collected their samples. The sample collection was approved by the hospital's ethics committee (approval number: 57, approved on 31 July 2015), and we obtained written informed consent from all study participants. This study was conducted in accordance with the Declaration of Helsinki guidelines. Table S1 summarizes the patients' characteristics.

\subsection{Cell Line and Cell Culture}

IM-9 cells (Cat\# JCRB0024, RRID: CVCL_1305), human myeloma cells, were purchased from the Japanese Collection of Research Bioresources Cell Bank/National Institute of Health Sciences (Tokyo, Japan). In addition, KMS-11 (RRID: CVCL_2989), KMS-12-PE (RRID: CVCL_1333), and KHM-11 (RRID: CVCL_A633) cells were kindly provided by Drs. Hata and Kawano, the Department of Hematology, Kumamoto University (Kumamoto, Japan) [6]. The cell lines were maintained in RPMI-1640 (Sigma-Aldrich, St. Louis, MO, USA), supplemented with $10 \%$ fetal bovine serum (FBS) (Gibco, Grand Island, NY, USA), $100 \mathrm{U}$ penicillin, and $100 \mu \mathrm{g} / \mathrm{mL}$ streptomycin (Gibco, Grand Island, $\mathrm{NY}$, USA) and cultured in an atmosphere containing $5 \% \mathrm{CO}_{2}$ at $37^{\circ} \mathrm{C}$. The medium was renewed two times a week. As described elsewhere [8,23]. we cultured rat INS-1 insulinoma cells with DOX-inducible expression of wild-type mouse IRE1 $\alpha$ in RPMI-1640, 10\% FBS, 1-mM sodium pyruvate, 10-mM HEPES, 2-mM glutamine, and 50- $\mu \mathrm{M} \beta$-mercaptoethanol; these cells were also grown in 5\% $\mathrm{CO}_{2}$ at $37^{\circ} \mathrm{C}$ and passed by trypsinization when they reached $>80 \%$ confluence. The culture medium was changed every $2-3$ days.

\subsection{Reagents}

KIRA8 was house-made as previously reported [10]. Bortezomib (CAS\#179324-69-7) was purchased from AdooQ BioScience (Irvine, CA, USA), thapsigargin (CAS\#67526-95-8) from Sigma-Aldrich (St. Louis, MO, USA), and nilotinib (CAS\#641571-10-0) from MedChemExpress (Monmouth, NJ, USA). Two PERK inhibitors, GSK2606414 (CAS\#1337531-89-1) and AMG PERK 44 (AMG; CAS\# 1883548-84-2), and dominant Polo-like kinase 2 (PLK2) inhibitor TC-S 7005 (CAS\#1082739-92-1) were purchased from TOCRIS Bioscience (Bristol, UK). All reagents were dissolved in dimethyl sulfoxide (DMSO) to a final concentration of $10 \mathrm{mM}$ as a stock solution and stored at $-30{ }^{\circ} \mathrm{C}$. 


\subsection{Cell Viability Assay}

The CCK-8 from Dojindo (Tokyo, Japan) was used to measure the cell viability. IM-9 cells were seeded into a 96-well plate, with a density of $8 \times 10^{3}$ cells/well. Then, the cells were treated as indicated with each drug for 24 or $72 \mathrm{~h}$. Briefly, we added $10 \mu \mathrm{L}$ CCK-8 solution to each well, and the plates were incubated for an additional $2 \mathrm{~h}$ at $37^{\circ} \mathrm{C}$. The optical densities at 450 and $650 \mathrm{~nm}$ were measured in a Corona plate reader SH-9000 (Hitachi, Tokyo, Japan). Then, the cell viability of the IM-9 cells was further confirmed using the trypan blue dye exclusion assay. The cells $\left(2 \times 10^{5}\right.$ cells $\left./ \mathrm{mL}\right)$ were inoculated into a 12-well plate and administered vehicle (DMSO) or KIRA8 $(0.1$ to $10 \mu \mathrm{M})$ for $60 \mathrm{~min}(\mathrm{~min})$ followed by bortezomib ( $5 \mathrm{nM}$ or $10 \mathrm{nM}$ ) or thapsigargin $(500 \mathrm{nM})$ for $24 \mathrm{~h}$, respectively. Next, the cells were stained with $0.4 \%$ trypan blue solution (Gibco, Grand Island, NY, USA), and the viable cells were counted using a hemocytometer counting chamber (Burker-turk, Erma Inc, Tokyo, Japan).

\subsection{Apoptosis Assay by Flow Cytometry}

We determined the apoptosis of myeloma cells using the annexin V-FITC Apoptosis Detection Kit (APOAF; Sigma-Aldrich, St. Louis, MO, USA) per the manufacturer's instructions. Briefly, the cells were collected and resuspended in a binding buffer after washing with phosphate-buffered saline, and $0.5 \mu \mathrm{L}$ fluorochrome-conjugated annexin $\mathrm{V}$ and $1 \mu \mathrm{L}$ propidium iodide (PI) solution was added into $100 \mu \mathrm{L}$ of cell suspension to incubate for $20 \mathrm{~min}$ at room temperature (RT) in the dark. Then, we calculated the percentage of apoptotic cells by flow cytometry analysis using FACSCalibur ${ }^{\mathrm{TM}}$ and FACSVerse ${ }^{\mathrm{TM}}$ Flow Cytometer (BD Biosciences, San Jose, CA, USA). The data analysis was performed using the FlowJo software v10.4.2 (Tree Star, Ashland, OR, USA). We defined the annexin-V positive/PI negative cells as cells in apoptosis.

\subsection{Extraction of the Total RNA, Quantitative Real-Time Polymerase Chain Reaction, and the Detection of XBP1 Splicing}

The total RNA of human myeloma cell lines and BM samples isolated by Ficoll solution (Histopaque-1077 ${ }^{\circledR}$; Sigma-Aldrich, St. Louis, MO, USA) was extracted using the RNeasy Mini Kit (Qiagen, Hilden, Germany) and reverse-transcribed to complementary DNA (cDNA) using the Omniscript Reverse Transcription Kit (Qiagen, Hilden, Germany). The samples were stored at $-80^{\circ} \mathrm{C}$. We evaluated the purity and quality of the total RNA spectrophotometrically using NanoDrop One (Thermo Fisher Scientific, Tokyo, Japan). In addition, the quantitative RT-PCR was performed using the PowerUp SYBR Green Master Mix (Applied Biosystems, Foster City, CA, USA). All quantitative calculations were performed using the $\Delta \Delta \mathrm{Ct}$ methods. Table S2 lists the nucleotide sequences of primers used for PCR [36]. The gene expression levels were normalized with the expression of the housekeeping gene, $A C T B$. The amplification reactions were initiated by incubation at $95^{\circ} \mathrm{C}$ for $5 \mathrm{~min}$, followed by a three-step amplification at $95{ }^{\circ} \mathrm{C}$ for $15 \mathrm{~s}(\mathrm{~s}), 60^{\circ} \mathrm{C}$ for $15 \mathrm{~s}$, and $72{ }^{\circ} \mathrm{C}$ for $60 \mathrm{~s}$ for 40 cycles. All reactions were performed in triplicate. The XBP1 mRNA processing was measured by amplifying the XBP1 CDNA with the primers: XBP1 5' -AAACAGAGTAGCAGCTCAGACTGC- $3^{\prime}$ and 5'-GGATCTCTAAAACTAGAGGCTTGGTG-3'. The PCR products of XBP1 cDNA were digested with $P$ stI, resolved on a $3 \%$ agarose gel, and stained with ethidium bromide $[10,23]$.

\subsection{RNA-Seq and Gene Expression Analysis}

For the RNA-seq analysis, we isolated the total RNA as described previously. The samples were collected in duplicates from IM-9 cells treated with DMSO (as a control), 10- $\mu$ M KIRA8 alone, and its combination treatment with $5 \mathrm{nM}$ bortezomib or $500 \mathrm{nM}$ thapsigargin. Using an Agilent Bioanalyzer 2100 and an RNA 6000 Nano Kit (Agilent Technologies, Santa Clara, CA, USA), the RNA integrity number (RIN) and concentration were determined. Then, 500 ng of total RNA (RIN > 8) of each sample was used for the cDNA library construction using a TruSeq Stranded mRNA Library Kit (Illumina Inc., San Diego, CA, USA) per the supplier's protocol. In addition, the paired-end sequencing of cDNA 
libraries was obtained using the Illumina HiSeq 2500 sequencing platform with a 125-bp read length. The gene expression analysis, including hierarchical clustering and top 30 most downregulated genes, was performed by Genble Inc. (Fukuoka, Japan). Next, the image output data from the sequencer were transformed into raw sequence data by base calling and stored in the FASTQ format.

Quality-controlled FASTQ sequences were trimmed using Prinseq-lite and Trimmomatic to remove poly (A/T) tails and low-quality reads, followed by mapping to the reference human genome GRCh38.p12 by STAR and measuring the transcript expression level in transcripts per million (TPM) with RNA-seq by expectation-maximization. Briefly, the samples were first grouped to compared with the pairwise control-treatment groups. Next, hierarchical clustering was calculated using the furthest neighbor method, with an averaged transcript expression level (TPM $>3, n=2)$, and the results were displayed in the heatmap. The differentially expressed genes (DEGs) were screened per the following default criteria: fold change $\geq 2$ and $\leq 0.5$. Table S3 shows the raw data.

\subsection{Cell-Cycle Analysis}

IM-9 cells were centrifuged at $230 \times g$ for $5 \mathrm{~min}$, and the supernatants were removed. Whilst vortexing, we gradually added $1 \mathrm{~mL}$ of ice-cold $70 \%$ ethanol and then fixed overnight at $4{ }^{\circ} \mathrm{C}$. The fixed cells were centrifuged at $1000 \times \mathrm{g}$ for $10 \mathrm{~min}$, and the residual ethanol in the conical tube was left. Each sample was incubated in $1.0 \mathrm{~mL}$ of staining solution containing $1 \mathrm{mg} / \mathrm{mL}$ RNase and $50-\mu \mathrm{g} / \mathrm{mL}$ propidium iodide (Sigma-Aldrich, St. Louis, MO, USA) for $>30 \mathrm{~min}$ at RT in the dark, and finally analyzed on the FACSCalibur ${ }^{\mathrm{TM}}$ and FACSVerse ${ }^{\mathrm{TM}}$ Flow Cytometer (BD Biosciences, San Jose, CA, USA). We calculated the percentage of cells in each phase of the cell cycle using the following method. At the peak of DNA content, $2 \mathrm{~N}$ was defined as the $\mathrm{G}_{0} / \mathrm{G}_{1}$ phase, $4 \mathrm{~N}$ as the $\mathrm{G}_{2} / \mathrm{M}$ phase, and the area between both peaks was defined as the $S$ phase. Then, the respective cell cycle ratios were calculated by twice the area smaller than $2 \mathrm{~N}$ as the $\mathrm{G}_{0} / \mathrm{G}_{1}$ phase, and twice the area larger than $4 \mathrm{~N}$ as the $G_{2} / M$ phase, and the remaining proportion as the $S$ phase.

\subsection{Western Blotting}

Briefly, human myeloma cells were lysed completely in Laemmli Sample Buffer with 2-mercaptoethanol (196-11022; Wako, Osaka, Japan) and were heated in a boiling water bath for $5 \mathrm{~min}$. The samples were separated in sodium dodecyl sulphate-polyacrylamide gel electrophoresis (SDS-PAGE) and transferred to polyvinylidene fluoride membranes. To detect the PLK2 protein, the blots were incubated overnight at $4{ }^{\circ} \mathrm{C}$ with rabbit anti-human PLK2 polyclonal antibody (Thermo Fisher Scientific, Tokyo, Japan; Cat\# PA5-14094, RRID:AB_2167742, 1:200 dilution) or rabbit anti-human PLK2 monoclonal antibody (Cell Signaling Technology, Berverly, MA, USA; Cat\# 14812, RRID:AB_2798626, 1:500 dilution) for the samples obtained from INS1 cells. Then, the blots were incubated with horseradish peroxidase (HRP)-conjugated goat anti-rabbit IgG polyclonal antibody (Abcam, Toronto, ON, Canada; Cat\# ab6721, RRID: AB_955447, 1:1000 dilution) at RT for $1 \mathrm{~h}$. To detect $\beta$-actin, we used mouse anti-human $\beta$-actin monoclonal antibody (Sigma-Aldrich, St. Louis, MO, USA; Cat\# A2228, RRID: AB_476697, 1:1000 dilution) and HRP-conjugated rabbit anti-mouse IgG antibody (Innovative Research, Novi, MI, USA; Cat\# 61-6020, RRID:AB_88249, 1:1000 dilution) as primary and secondary antibodies, respectively. The protein bands were visualized by SuperSignal ${ }^{\circledR}$ West Dura Substrate (Thermo Fisher Scientific, Tokyo, Japan) and exposed to X-ray film (FUJIFILM Medical Systems, Tokyo, Japan). We measured the band intensities using Image J software version $1.51 \mathrm{k}$ (National Institutes of Health, Bethesda, MD, USA). Notably, the $\beta$-actin level was used as an internal control to ensure equal amounts of loading proteins.

\subsection{Immunohistochemical Analysis}

We performed immunohistochemical analysis on formalin-fixed BM clots obtained from patients with NDMM [37,38]. In addition, we performed antigen retrieval using a microwave and a citrate buffer ( $\mathrm{pH}$ 6.0). Then, tissue samples were incubated at RT for $60 \mathrm{~min}$ with an antibody specific 
for PLK2 (Thermo Fisher Scientific, Tokyo, Japan, Cat\# PA5-14094, RRID: AB_2167742, 1:100 dilution). Next, DAB (3,3'-diaminobenzidine) staining was performed using the two-step EnVision+ System-HRP methodology (Dako, Tokyo, Japan) and reacted with hematoxylin. For double-label fluorescent immunohistochemistry, the samples were reacted with Cy2-conjugated goat anti-rabbit IgG polyclonal antibody (Jackson ImmunoResearch Labs, West Grove, PA, USA; Cat\# 111-225-144, RRID: AB_2338021, 1:400 dilution) and PE-labelled mouse anti-human CD138 monoclonal antibody (BioLegend, San Diego, CA, USA; Cat\# 352306, RRID: AB_10901158, 1:10 dilution). Finally, we used DAPI (4' ,6-diamidino-2-phenylindole) as nuclear staining. Light and fluorescent images were captured using a BIOREVO BZ-X800 fluorescence microscope (Keyence, Tokyo, Japan).

\subsection{Statistical Analysis}

All experiments in this study were independently repeated, at least three times. The sample number is indicated in figures and figure legends. All values were expressed as the mean \pm standard error of the mean (SEM). All statistical analyses were performed using GraphPad Prism version 6.00 (GraphPad Software Inc., San Diego, CA, USA) and JMP ${ }^{\circledR}$ Pro 14 (SAS Institute Inc., Cary, NC, USA). In addition, Student's $t$-test or one-way analysis of variance, followed by post-hoc Tukey's test, were used to assess the statistical difference between two groups or between more than two groups, respectively, unless otherwise noted. Statistical significance was considered at $p<0.05$.

Supplementary Materials: The following are available online at http://www.mdpi.com/1422-0067/21/17/6314/s1, Figure S1: Trypan Blue Exclusion Assay Data; Table S1: Clinical characteristics of our patients in this study; Table S2: qRT-PCR primer sequences; Table S3: Gene Expression; Table S4: Gene Ontology (GO) term enrichment analysis.

Author Contributions: Y.Y., S.M. and S.T. designed and performed the research, analyzed the data, and wrote the paper; H.H., H.K., S.K. and T.I. performed the molecular analyses; B.J.B. made KIRA8; H.M. and A.K. analyzed the RNA-seq data; K.-I.Y., F.R.P. and T.S. supervised the project and wrote the paper. All authors have read and agreed to the published version of the manuscript.

Funding: This work was supported by grants (18K16242, 19K08821, 19K17839, 20K08718, and 20K17405) from the Ministry of Education, Culture, Sports, Science, and Technology of Japan, the Ministry of Labor and Welfare of Japan, and The Japanese Society of Hematology Research Grant (2018 and 2019).

Acknowledgments: We thank Hata and Kawano at the Department of Hematology, Kumamoto University, for kindly providing KMS-11, KMS-12-PE, and KHM-11 cells used in this study.

Conflicts of Interest: The authors declare no conflict of interest. The funding sources of this study did not play any role in the study design, the collection, analysis and interpretation of the data, in the writing of the manuscript, or in the decision to submit the paper for publication. Furthermore, the corresponding author confirms having full access to all the data in the study and the final responsibility for the decision to submit for publication.

\section{References}

1. Chim, C.S.; Kumar, S.K.; Orlowski, R.Z.; Cook, G.; Richardson, P.G.; Gertz, M.A.; Giralt, S.; Mateos, M.V.; Leleu, X.; Anderson, K.C. Management of relapsed and refractory multiple myeloma: Novel agents, antibodies, immunotherapies and beyond. Leukemia 2018, 32, 252-262. [CrossRef] [PubMed]

2. Nikesitch, N.; Lee, J.M.; Ling, S.; Roberts, T.L. Endoplasmic reticulum stress in the development of multiple myeloma and drug resistance. Clin. Transl. Immunol. 2018, 7, e1007. [CrossRef]

3. Ri, M. Endoplasmic-reticulum stress pathway-associated mechanisms of action of proteasome inhibitors in multiple myeloma. Int. J. Hematol. 2016, 104, 273-280. [CrossRef]

4. Vincenz, L.; Jager, R.; O’Dwyer, M.; Samali, A. Endoplasmic reticulum stress and the unfolded protein response: Targeting the Achilles heel of multiple myeloma. Mol. Cancer Ther. 2013, 12, 831-843. [CrossRef] [PubMed]

5. Iwakoshi, N.N.; Lee, A.H.; Vallabhajosyula, P.; Otipoby, K.L.; Rajewsky, K.; Glimcher, L.H. Plasma cell differentiation and the unfolded protein response intersect at the transcription factor XBP-1. Nat. Immunol. 2003, 4, 321-329. [CrossRef] [PubMed]

6. Nakamura, M.; Gotoh, T.; Okuno, Y.; Tatetsu, H.; Sonoki, T.; Uneda, S.; Mori, M.; Mitsuya, H.; Hata, H. Activation of the endoplasmic reticulum stress pathway is associated with survival of myeloma cells. Leuk. Lymphoma 2006, 47, 531-539. [CrossRef] [PubMed] 
7. Carrasco, D.R.; Sukhdeo, K.; Protopopova, M.; Sinha, R.; Enos, M.; Carrasco, D.E.; Zheng, M.; Mani, M.; Henderson, J.; Pinkus, G.S.; et al. The differentiation and stress response factor XBP-1 drives multiple myeloma pathogenesis. Cancer Cell 2007, 11, 349-360. [CrossRef] [PubMed]

8. Ghosh, R.; Wang, L.; Wang, E.S.; Perera, B.G.; Igbaria, A.; Morita, S.; Prado, K.; Thamsen, M.; Caswell, D.; Macias, H.; et al. Allosteric inhibition of the IRE1alpha RNase preserves cell viability and function during endoplasmic reticulum stress. Cell 2014, 158, 534-548. [CrossRef]

9. Ishibashi, T.; Morita, S.; Kishimoto, S.; Uraki, S.; Takeshima, K.; Furukawa, Y.; Inaba, H.; Ariyasu, H.; Iwakura, H.; Furuta, H.; et al. Nicotinic acetylcholine receptor signaling regulates inositol-requiring enzyme $1 \alpha$ activation to protect $\beta$-cells against terminal unfolded protein response under irremediable endoplasmic reticulum stress. J. Diabetes Investig. 2020, 11, 801-813. [CrossRef] [PubMed]

10. Morita, S.; Villalta, S.A.; Feldman, H.C.; Register, A.C.; Rosenthal, W.; Hoffmann-Petersen, I.T.; Mehdizadeh, M.; Ghosh, R.; Wang, L.; Colon-Negron, K.; et al. Targeting ABL-IRE1 $\alpha$ Signaling Spares ER-Stressed Pancreatic $\beta$ Cells to Reverse Autoimmune Diabetes. Cell Metab. 2017, 25, 883-897.e8. [CrossRef]

11. Harrington, P.E.; Biswas, K.; Malwitz, D.; Tasker, A.S.; Mohr, C.; Andrews, K.L.; Dellamaggiore, K.; Kendall, R.; Beckmann, H.; Jaeckel, P.; et al. Unfolded Protein Response in Cancer: IRE1alpha Inhibition by Selective Kinase Ligands Does Not Impair Tumor Cell Viability. ACS Med. Chem. Lett. 2015, 6, 68-72. [CrossRef]

12. Cubillos-Ruiz, J.R.; Bettigole, S.E.; Glimcher, L.H. Tumorigenic and Immunosuppressive Effects of Endoplasmic Reticulum Stress in Cancer. Cell 2017, 168, 692-706. [CrossRef] [PubMed]

13. Chen, L.; Li, Q.; She, T.; Li, H.; Yue, Y.; Gao, S.; Yan, T.; Liu, S.; Ma, J.; Wang, Y. IRE1alpha-XBP1 signaling pathway, a potential therapeutic target in multiple myeloma. Leuk. Res. 2016, 49, 7-12. [CrossRef] [PubMed]

14. Harnoss, J.M.; Le Thomas, A.; Shemorry, A.; Marsters, S.A.; Lawrence, D.A.; Lu, M.; Chen, Y.A.; Qing, J.; Totpal, K.; Kan, D.; et al. Disruption of IRE1alpha through its kinase domain attenuates multiple myeloma. Proc. Natl. Acad. Sci. USA 2019, 116, 16420-16429. [CrossRef] [PubMed]

15. Anthony, T.G.; Wek, R.C. TXNIP switches tracks toward a terminal UPR. Cell Metab. 2012, 16, $135-137$. [CrossRef] [PubMed]

16. Lerner, A.G.; Upton, J.P.; Praveen, P.V.; Ghosh, R.; Nakagawa, Y.; Igbaria, A.; Shen, S.; Nguyen, V.; Backes, B.J.; Heiman, M.; et al. IRE1alpha induces thioredoxin-interacting protein to activate the NLRP3 inflammasome and promote programmed cell death under irremediable ER stress. Cell Metab. 2012, 16, 250-264. [CrossRef]

17. Moore, P.C.; Qi, J.Y.; Thamsen, M.; Ghosh, R.; Peng, J.; Gliedt, M.J.; Meza-Acevedo, R.; Warren, R.E.; Hiniker, A.; Kim, G.E.; et al. Parallel Signaling through IRE1alpha and PERK Regulates Pancreatic Neuroendocrine Tumor Growth and Survival. Cancer Res. 2019, 79, 6190-6203. [CrossRef]

18. Smith, A.L.; Andrews, K.L.; Beckmann, H.; Bellon, S.F.; Beltran, P.J.; Booker, S.; Chen, H.; Chung, Y.A.; D'Angelo, N.D.; Dao, J.; et al. Discovery of 1H-pyrazol-3(2H)-ones as potent and selective inhibitors of protein kinase R-like endoplasmic reticulum kinase (PERK). J. Med. Chem. 2015, 58, 1426-1441. [CrossRef]

19. Axten, J.M.; Medina, J.R.; Feng, Y.; Shu, A.; Romeril, S.P.; Grant, S.W.; Li, W.H.; Heerding, D.A.; Minthorn, E.; Mencken, T.; et al. Discovery of 7-methyl-5-(1-\{[3-(trifluoromethyl)phenyl]acetyl\}-2,3-dihydro-1H-indol-5-yl)-7H-p yrrolo[2,3-d]pyrimidin-4-amine (GSK2606414), a potent and selective first-in-class inhibitor of protein kinase $\mathrm{R}$ (PKR)-like endoplasmic reticulum kinase (PERK). J. Med. Chem. 2012, 55, 7193-7207. [CrossRef]

20. Newbatt, Y.; Hardcastle, A.; McAndrew, P.C.; Strover, J.A.; Mirza, A.; Morgan, G.J.; Burke, R.; Davies, F.E.; Collins, I.; van Montfort, R.L. Identification of autophosphorylation inhibitors of the inositol-requiring enzyme 1 alpha (IRE1 $\alpha$ ) by high-throughput screening using a DELFIA assay. J. Biomol. Screen. 2013, 18, 298-308. [CrossRef]

21. Zitouni, S.; Nabais, C.; Jana, S.C.; Guerrero, A.; Bettencourt-Dias, M. Polo-like kinases: Structural variations lead to multiple functions. Nat. Rev. Mol. Cell Biol. 2014, 15, 433-452. [CrossRef] [PubMed]

22. Gjertsen, B.T.; Schoffski, P. Discovery and development of the Polo-like kinase inhibitor volasertib in cancer therapy. Leukemia 2015, 29, 11-19. [CrossRef] [PubMed]

23. Han, D.; Lerner, A.G.; Vande Walle, L.; Upton, J.P.; Xu, W.; Hagen, A.; Backes, B.J.; Oakes, S.A.; Papa, F.R. IRE1alpha kinase activation modes control alternate endoribonuclease outputs to determine divergent cell fates. Cell 2009, 138, 562-575. [CrossRef] [PubMed]

24. Huang, S.; Xing, Y.; Liu, Y. Emerging roles for the ER stress sensor IRE1 $\alpha$ in metabolic regulation and disease. J. Biol. Chem. 2019, 294, 18726-18741. [CrossRef] 
25. Hanan, E.J.; Fucini, R.V.; Romanowski, M.J.; Elling, R.A.; Lew, W.; Purkey, H.E.; VanderPorten, E.C.; Yang, W. Design and synthesis of 2-amino-isoxazolopyridines as Polo-like kinase inhibitors. Bioorg. Med. Chem. Lett. 2008, 18, 5186-5189. [CrossRef]

26. Bagratuni, T.; Wu, P.; Gonzalez de Castro, D.; Davenport, E.L.; Dickens, N.J.; Walker, B.A.; Boyd, K.; Johnson, D.C.; Gregory, W.; Morgan, G.J.; et al. XBP1s levels are implicated in the biology and outcome of myeloma mediating different clinical outcomes to thalidomide-based treatments. Blood 2010, 116, 250-253. [CrossRef]

27. Gambella, M.; Rocci, A.; Passera, R.; Gay, F.; Omede, P.; Crippa, C.; Corradini, P.; Romano, A.; Rossi, D.; Ladetto, M.; et al. High XBP1 expression is a marker of better outcome in multiple myeloma patients treated with bortezomib. Haematologica 2014, 99, e14-e16. [CrossRef]

28. Papandreou, I.; Denko, N.C.; Olson, M.; Van Melckebeke, H.; Lust, S.; Tam, A.; Solow-Cordero, D.E.; Bouley, D.M.; Offner, F.; Niwa, M.; et al. Identification of an Ire1alpha endonuclease specific inhibitor with cytotoxic activity against human multiple myeloma. Blood 2011, 117, 1311-1314. [CrossRef]

29. Mimura, N.; Fulciniti, M.; Gorgun, G.; Tai, Y.T.; Cirstea, D.; Santo, L.; Hu, Y.; Fabre, C.; Minami, J.; Ohguchi, H.; et al. Blockade of XBP1 splicing by inhibition of IRE1alpha is a promising therapeutic option in multiple myeloma. Blood 2012, 119, 5772-5781. [CrossRef] [PubMed]

30. Xie, H.; Tang, C.H.; Song, J.H.; Mancuso, A.; Del Valle, J.R.; Cao, J.; Xiang, Y.; Dang, C.V.; Lan, R.; Sanchez, D.J.; et al. IRE1alpha RNase-dependent lipid homeostasis promotes survival in Myc-transformed cancers. J. Clin. Investig. 2018, 128, 1300-1316. [CrossRef]

31. Mateos, M.V.; San Miguel, J.F. Management of multiple myeloma in the newly diagnosed patient. Hematology 2017, 2017, 498-507. [CrossRef]

32. Weisberg, E.; Manley, P.W.; Breitenstein, W.; Brüggen, J.; Cowan-Jacob, S.W.; Ray, A.; Huntly, B.; Fabbro, D.; Fendrich, G.; Hall-Meyers, E.; et al. Characterization of AMN107, a selective inhibitor of native and mutant Bcr-Abl. Cancer Cell 2005, 7, 129-141. [CrossRef]

33. Goroshchuk, O.; Kolosenko, I.; Vidarsdottir, L.; Azimi, A.; Palm-Apergi, C. Polo-like kinases and acute leukemia. Oncogene 2019, 38, 1-16. [CrossRef]

34. Xie, Y.; Liu, Y.; Li, Q.; Chen, J. Polo-like kinase 2 promotes chemoresistance and predicts limited survival benefit from adjuvant chemotherapy in colorectal cancer. Int. J. Oncol. 2018, 52, 1401-1414. [CrossRef] [PubMed]

35. Rajkumar, S.V.; Harousseau, J.L.; Durie, B.; Anderson, K.C.; Dimopoulos, M.; Kyle, R.; Blade, J.; Richardson, P.; Orlowski, R.; Siegel, D.; et al. Consensus recommendations for the uniform reporting of clinical trials: Report of the International Myeloma Workshop Consensus Panel 1. Blood 2011, 117, 4691-4695. [CrossRef] [PubMed]

36. Morita, S.; Takeshima, K.; Ariyasu, H.; Furukawa, Y.; Kishimoto, S.; Tsuji, T.; Uraki, S.; Mishima, H.; Kinoshita, A.; Takahashi, Y.; et al. Expression of unfolded protein response markers in the pheochromocytoma with Waardenburg syndrome: A case report. BMC Endocr. Disord. 2020, 20, 90. [CrossRef] [PubMed]

37. Matsue, K.; Matsue, Y.; Kumata, K.; Usui, Y.; Suehara, Y.; Fukumoto, K.; Fujisawa, M.; Narita, K.; Takeuchi, M. Quantification of bone marrow plasma cell infiltration in multiple myeloma: Usefulness of bone marrow aspirate clot with CD138 immunohistochemistry. Hematol. Oncol. 2017, 35, 323-328. [CrossRef]

38. Tamura, S.; Morikawa, Y.; Miyajima, A.; Senba, E. Expression of oncostatin M receptor beta in a specific subset of nociceptive sensory neurons. Eur. J. Neurosci. 2003, 17, 2287-2298. [CrossRef]

(C) 2020 by the authors. Licensee MDPI, Basel, Switzerland. This article is an open access article distributed under the terms and conditions of the Creative Commons Attribution (CC BY) license (http://creativecommons.org/licenses/by/4.0/). 